\title{
Epigenetic modification suppresses proliferation, migration and invasion of urothelial cancer cell lines
}

\author{
PHILLIPP BROCKMEYER ${ }^{1}$ and BERNHARD HEMMERLEIN ${ }^{2,3}$ \\ Departments of ${ }^{1}$ Oral and Maxillofacial Surgery, and ${ }^{2}$ Pathology, University Medical Centre Göttingen, \\ Göttingen D-37075; ${ }^{3}$ Department of Pathology, Helios Klinikum Krefeld, Krefeld D-47805, Germany
}

Received September 5, 2015; Accepted May 23, 2016

DOI: 10.3892/ol.2016.4877

\begin{abstract}
Epigenetic approaches offer additional therapeutic options, including apoptosis induction, modification of cell cycle regulating proteins and the re-expression of pharmaceutical targets, such as hormone receptors. The present study analyzed the effect of the epigenetic modifiers 5-aza-2'-deoxycytidine and Trichostatin A on the proliferative, migratory and invasive behavior of four urinary bladder cancer cell lines (RT-4, RT-112, VMCUB-1 and T-24), and the expression of various matrix metalloproteinases (MMPs) and tissue inhibitors of matrix metalloproteinases (TIMPs). Cell proliferation, migration and invasion assays revealed that treatment with the two epigenetic modifiers resulted in proliferation inhibition in all cell lines, and migration and invasion inhibition in RT-4, RT-112 and T-24 cell lines. Quantitative polymerase chain reaction demonstrated that the mRNA expression of a broad selection of MMPs and their TIMPs was induced in all cell lines, and MMP-14 mRNA expression was suppressed in all cell lines, with the exception of RT-4. In conclusion, epigenetic modifications suppressed the motility and invasiveness of three out of four urothelial cancer cell lines. The inhibitory effect on cell motility appears to be crucial for reduced invasive properties. However, even a broad spectrum of mRNA analysis does not sufficiently explain the loss of invasiveness, as it does not allow for functional conclusions. Further complex urothelial tumour models should be applied to investigate whether epigenetic therapeutic approaches may be an option in urothelial cancer.
\end{abstract}

Correspondence to: Dr Bernhard Hemmerlein, Department of Pathology, Helios Klinikum Krefeld, 40 Lutherplatz, Krefeld D-47805, Germany

E-mail: bernhard.hemmerlein@helios-kliniken.de hemmerlein.bernhard@t-online.de

Key words: urothelial cancer cell lines, epigenetic modification, 5-aza-2'-deoxycytidine, Trichostatin A, proliferation, migration, invasion, matrix metalloproteinases, tissue inhibitors of matrix metalloproteinases

\section{Introduction}

Epigenetic modifications affect gene expression without altering the DNA structure. DNA methylation and histone acetylation, or methylation, are two of the most important mechanisms. Epigenetic gene expression modulation is an aspect of physiological development, and its dysregulation is involved in carcinogenesis (1). In myelodysplastic syndromes and acute myeloid leukemia, epigenetic modifiers are used in routine therapy $(2,3)$, and such approaches are becoming popular treatment options for solid tumours (4). Epidermal growth factor receptor is downregulated by epigenetic modifications, and the re-expressed receptor after treatment with, for example, hypomethylating agents is a potential therapeutic target leading to cell death $(5,6)$. Several studies have demonstrated the growth-inhibiting effect of Trichostatin A (TSA) on carcinomas $(7,8)$. Vigushin et al (7) described histone hyperacetylation of histone $\mathrm{H} 4$, thereby inhibiting proliferation in breast cancer cell lines following TSA treatment. Ailenberg and Silverman (8) described apoptosis induction in tumour cells following TSA treatment, which restored the expression of cell-cycle-controlling genes.

The compound 5-aza-2'-deoxycytidine (aza) is a cytosin analogue, which can be integrated into newly synthesised DNA strands. Aza irreversibly binds and inhibits DNA (cytosine-5)-methyltransferase 1 (DNMT1), which transfers methylation patterns to newly synthesised DNA. Loss of DNMT1 activity therefore leads to a loss of methylation during the next cell cycles and the re-expression of specific genes (9). Methylation inhibition of $\mathrm{CpG}$ islands of the estrogen receptor leads to its downregulation, and treatment with aza restores estrogen receptor expression (10). This principle has been demonstrated for numerous other genes, including e-cadherin in ovarian cancer (11) or tissue inhibitor of matrixmetalloproteinase (TIMP)-3 in gastric cancer (12).

Urothelial cancer develops from a preinvasive stage into an invasive cancer capable of developing metastasis. Matrix metalloproteinases (MMPs) are key molecules in extracellular remodelling, and are most likely to be important for the step from non-invasive to invasive urothelial cancer (13). MMP-9 was previously shown to be upregulated in invasive cancer compared with superficial bladder carcinomas (13). Furthermore, certain studies have shown that the increased expression of MMP-9 and TIMP-2 is associated with an 
increased recurrence rate of superficial bladder cancer (14). Depending on the grade of differentiation and stage, urothelial cancer may be treated by local chemo- or immunotherapy (15). However, intravesical treatment, either by instillation of Mitomycin $\mathrm{C}$ or intravesical immunotherapy by induction of an inflammation with Bacillus Calmette-Guérin (BCG), holds the potential of severe adverse effects, including severe urocystitis or even systemic BCG infections $(16,17)$. Epigenetic approaches may offer potential therapeutic options for urothelial cancer. Nevertheless, such modifiers also indirectly affect the expression of genes, which are not under the influence of $\mathrm{CpG}$ islands in their promoter regions.

The present study analyzed the effect of the epigenetic modifiers aza and TSA on the proliferation, migration and invasion of four biologically different human urinary bladder cancer cell lines (RT-4, RT-112, VMCUB-1, T-24). In addition, the mRNA expression of various MMPs, TIMPs and extracellular matrix metalloproteinase inducer (EMMPRIN) was analyzed in the four cell lines following aza and TSA treatment.

\section{Materials and methods}

Cell culture. Human urinary bladder transitional cell papilloma RT-4 and human urinary bladder transitional cell carcinoma RT-112 (low-grade), VMCUB-1 and T-24 (high grade) cell lines were obtained from the German Collection of Cell Cultures and Microorganisms (Braunschweig, Germany). They were cultivated in Dulbecco's modified Eagle's medium (GE Healthcare, Chalfont, UK), supplemented with $10 \%$ foetal calf serum, $1 \%$ penicillin/streptomycin and $1 \%$ L-glutamine (all Sigma-Aldrich Chemie Gmbh, Munich, Germany) in a humidified incubator at $37^{\circ} \mathrm{C}$ with $5 \% \mathrm{CO}_{2}$.

Tumour doubling time. To calculate the tumour doubling time, $10^{5}$ cells were seeded in a $25-\mathrm{cm}^{2}$ flask and cell density was counted after 24 and $48 \mathrm{~h}$.

Cell proliferation and treatment with epigenetic modifiers. All measurements were performed in triplicate in three independent experiments. In total, 5,000 tumour cells were seeded per well in $200 \mu \mathrm{l}$ cell culture medium, and cultivated for $24 \mathrm{~h}$. For sole treatment with aza, cells were treated with $10 \mu \mathrm{Mol}$ aza for an additional $48 \mathrm{~h}$. For sole treatment with TSA, cells were stimulated with 200 nMol TSA for 24 h. For combined treatment, cells were sequentially stimulated with $10 \mu \mathrm{Mol}$ aza for $24 \mathrm{~h}$, after which, $200 \mathrm{nMol}$ TSA was added for an additional $24 \mathrm{~h}$. After stimulation, cell cultures were labelled for a further $14 \mathrm{~h}$ with bromodeoxyuridine (BrdU) at a final concentration of $10 \mu \mathrm{Mol}$. Proliferation analysis was performed using a BrdU-Cell Proliferation ELISA (Roche Diagnostics GmbH, Penzberg, Germany), according to the manufacturer's protocol. Absorbance was measured using a microplate reader (BioRad Laboratories, Inc., Hercules, CA, USA) at $450 \mathrm{~nm}$ (control wavelength $655 \mathrm{~nm}$ ).

Cell migration and invasion. Cell migration was analyzed using microwell inserts (pore size, $8-\mu \mathrm{m}$; Nunc ${ }^{\mathrm{TM}}$ Cell Culture Inserts; Thermo Fisher Scientific, Inc., Waltham, MA, USA), while cell invasion was analyzed using Corning ${ }^{\circledR}$ BioCoat $^{\mathrm{TM}}$
Growth Factor Reduced Matrigel Invasion Chambers (pore size, 8- $\mu \mathrm{m}$; BD Biosciences, Franklin Lakes, NsJ, USA). For the two assays, culture medium supplemented with $20 \%$ heat-inactivated foetal calf serum was used as a chemoattractant in the lower reservoir. All measurements were performed in three independent experiments using sequential treatment with aza and TSA. Negative controls were performed using acetic acid and dimethyl sulfoxide alone. Subsequent to $72 \mathrm{~h}$, pre-treated cells were harvested, washed and seeded in the upper reservoir. After $24 \mathrm{~h}$, cells on the lower side of the membrane were counted following staining with Giemsa. All values were corrected against the proliferation ratio of BrdU $($ aza + TSA) / BrdU (control).

Quantitative polymerase chain reaction ( $q P C R)$ analysis of MMP, TIMP and EMMPRIN expression. Total RNA was extracted from untreated cells and cells that were treated using the aforementioned method with the RNeasy Mini kit ${ }^{\circledR}$ (Qiagen GmbH, Hilden, Germany), according to the manufacturer's protocol. Since preliminary experiments did not reveal genomic DNA contamination, no RNAse treatment was performed. RNA integrity and concentration was determined using an Agilent 2100 Bioanalyzer (Agilent Technologies Deutschland GmbH \& Co., KG, Waldbronn, Germany). In total, $500 \mathrm{ng}$ total RNA were reverse transcribed into cDNA (Omniscript Reverse Transcriptase kit; Qiagen $\mathrm{GmbH}$ ). For specific gene expression, $125 \mathrm{ng}$ cDNA was subjected to qPCR using an iCycler $^{\circledR}$ (BioRad Laboratories, Inc.) with SYBR $^{\circledR}$-Green I as an intercalating dye (SYBR Green I Supermix; BioRad Laboratories, Inc.). For qPCR, 50 cycles were performed under the following conditions: Denaturation for $30 \mathrm{sec}$ at $95^{\circ} \mathrm{C}$; annealing for $30 \mathrm{sec}$ (for temperatures see Table I); followed by elongation for $30 \mathrm{sec}$ at $95^{\circ} \mathrm{C}$. Primer sequences were synthesized by Eurofins Genomics (Ebersberg, Germany) and are listed in Table I. All experiments were performed in triplicate, and specific reverse transcription-PCR measurements were performed in duplicate. The specificity of the PCR reaction was proven by melting point analysis and agarose gel electrophoresis. Expression values were calculated with reference to porphobilinogen deaminase gene expression using the $\Delta \Delta \mathrm{Cq}$ method $(\Delta \Delta \mathrm{Cq}=\Delta \Delta \mathrm{Cq}$ treated $-\Delta \Delta \mathrm{Cq}$ untreated control) and the equation $\mathrm{y}=2^{-\Delta \Delta \mathrm{Cq}}(18)$.

Statistical analysis. Statistical significance was calculated using Student's t-test. Post hoc comparisons were made by the Bonferroni test for repeated measurements. $\mathrm{P}<0.05$ was considered to indicate a statistically significant difference. All tests were performed using GraphPad Prism version 4 software (GraphPad Software Inc., La Jolla, CA, USA).

\section{Results}

Antiproliferative effects of epigenetic modifiers. The calculation of the tumour doubling time of unstimulated cell lines revealed a doubling time of $41.6 \mathrm{~h}$ for cell line RT-4, $15.9 \mathrm{~h}$ for RT-112, $11.3 \mathrm{~h}$ for VMCUB-1 and $9 \mathrm{~h}$ for T-24.

In cell lines RT-112 ( $\mathrm{P}=0.008), \mathrm{VMCUB}-1 \quad(\mathrm{P}=0.035)$ and $\mathrm{T}-24(\mathrm{P}=0.050)$ only combined aza and TSA treatment resulted in a significantly reduced proliferation compared with untreated controls. By contrast, the proliferation of RT-4 cells 
Table I. Primers used for quantitative polymerase chain reaction and their annealing temperatures.

\begin{tabular}{|c|c|c|c|}
\hline MMP type & Sense primer & Antisense primer & Temperature, ${ }^{\circ} \mathrm{C}$ \\
\hline MMP-1 & CTGGGAGCAAACACATCTGA & AAGGAGAGTTGTCCCGATGA & 63 \\
\hline MMP-2 & ACAGTGGACATGGCGGTCTCAG & AGCCAAGTGGTCCGTGTGAA & 62 \\
\hline MMP-3 & CCTTTTGATGGACCTGGAAA & TGAAAGAGACCCAGGGAGTG & 56 \\
\hline MMP-7 Ex4/5 & TGCTCACTTCGATGAGGATG & TGGGGATCTCCATTTCCATA & 59 \\
\hline MMP-8 & CTTTCAGGGAAACCAGCAAC & TCCACGGAGTGTGGTGATAG & 56 \\
\hline MMP-9 & GCCACTTGTCGGCGATAGG & CACTGTCCACCCCTCAGAGC & 63 \\
\hline MMP-10 & TGGGTTTTCCTCCAACCATA & AGGCTCAACTCCTGGAAAGTC & 59 \\
\hline MMP-11 & TGTGACGCCACTCACCTTTA & ATCCCCTTCTCGGTGAGTCT & 56 \\
\hline MMP-12 & $\begin{array}{l}\text { TTCCCCTGAACAGCTCTACAAGCC } \\
\text { TGGAAA }\end{array}$ & $\begin{array}{l}\text { GATCCAGGTCCAAAAGCATGGGCT } \\
\text { AGGATT }\end{array}$ & 65 \\
\hline MMP-13 & AACATCCAAAAACGCCAGAC & GGAAGTTCTGGCCAAAATGA & 53 \\
\hline MMP-14 & CGGTCATCATCGGGCAGCACAAAA & CGCTACGCCATCCAGGGTCTCAAA & 63 \\
\hline MMP-15 & GGAATTCCCCCTCATGTAT & GGGATCCCTTTCCAGACTGT & 63 \\
\hline MMP-16 & GGAATTCCCCCTCATGGTAT & GGGATCCCTTTCCAGACTGT & 63 \\
\hline MMP-17 & GTGTGCGGGAGTCTGTGTC & AAAGCTTCACCCCGGATCT & 68 \\
\hline MMP-19 & CACAATATGGGTACCTACAGAAGC & GATCCTCTAGGCCACAACGA & 59 \\
\hline MMP-20 & GCACGTGCAGCAAATAGATG & TCGATTTGGCCATTTACTCC & 56 \\
\hline MMP-21 Ex5/6 & ATGGGGACCCTATCCAAATC & GGTCATAAAACGCCGTGTCT & 59 \\
\hline MMP-23 & GATCAACCACACGGACTGC & CGTGTTGTGAGTGCATCAGG & 56 \\
\hline MMP-24 & CCTATGACTCACGGGCATCT & GCCTCCACTTCTGTCCAGTC & 59 \\
\hline MMP-25 & CCCAAACCCCATATGACAAG & AGGGGCCTTTGAAGAAGAAA & 56 \\
\hline MMP-26 & GATATGAAGCCATCCGCAGT & AGGCATGGCCTAAGATACCA & 63 \\
\hline MMP-27 & GCCAGATTATCCCAAATCC & TTACCACTCTCTGCGGGAAC & 59 \\
\hline MMP-28 & GAGACCTGGGACTCCTACAGC & CTCTGAGACGTTGCCATCAG & 61 \\
\hline TIMP-1 & ACCAGACCACCTTATACCAGCG & GGACTGGAAGCCCTTTTCAGAG & 65 \\
\hline TIMP-2 & ATGCAGATGTAGTGATCAGGGC & GATGAAGTCACAGAGGGTGATG & 63 \\
\hline TIMP-3 & GGGGAAGAAGCTGGTAAAG & AAGTCACAAAGCAAGGCAG & 57 \\
\hline TIMP-4 & CACCCTCAGCAGCACATCT & TTTGATTTCATACCGGAGCA & 59 \\
\hline EMMPRIN & CCGGCACAGTCTTCACTACC & TACTCTCCCCACTGGTCGTC & 60 \\
\hline PBGD & $\begin{array}{l}\text { TCAATGTTGCCACCACACTGTCCG } \\
\text { TCT }\end{array}$ & $\begin{array}{l}\text { TGTCTGGTAACGGCAATGCGGCTG } \\
\text { CAAC }\end{array}$ & 70 \\
\hline
\end{tabular}

MMP, matrix metalloproteinase; TIMP, tissue inhibitor matrix metalloproteinase; EMMPRIN, extracellular matrix metalloproteinase inducer; PBGD, porphobilinogen deaminase.

was significantly suppressed by treatment with TSA $(\mathrm{P}=0.009)$ or aza treatment alone $(\mathrm{P}=0.049)$, and the TSA and aza combination treatment $(\mathrm{P}=0.009)$ (Fig. 1).

Migration inhibition by epigenetic modifiers. Migration was significantly inhibited by combined treatment of aza and TSA in the low grade RT-4 ( $\mathrm{P}=0.004)$ and RT-112 $(\mathrm{P}=0.004)$ cell lines, and slightly less inhibited in the high grade $\mathrm{T}-24$ cell line $(\mathrm{P}=0.045)$. No significant difference was observed for VMCUB-1 cells ( $\mathrm{P}=0.092)$ (Fig. 2).

Invasion inhibition by epigenetic modifiers. Cell invasion was significantly inhibited by combined treatment of aza and TSA in the low grade RT-4 $(\mathrm{P}=0.001)$ and RT-112 $(\mathrm{P}=0.044)$ cell lines, and the high grade $\mathrm{T}-24$ cell line $(\mathrm{P}=0.013)$. No significant difference was observed in VMCUB-1 cells $(\mathrm{P}=0.552)$ (Fig. 3).
Effects of epigenetic modifiers on MMP, TIMP and EMMPRIN mRNA expression.

Overall. All data regarding smRNA expression levels and the effect of epigenetic modifiers are summarized in Fig. 4 and Table II.

EMMPRIN expression. TSA and aza induced a significant mRNA increase in the low-grade RT-4 $(\mathrm{P}=0.0254)$ and RT-112 $(\mathrm{P}=0.0193)$ cell lines. This induction was nearly significant in VMCUB-1 $(\mathrm{P}=0.0618)$ and $\mathrm{T}-24(\mathrm{P}=0.0518)$ cells.

Membrane-type (MT) MMPs. With the exception of RT-4 cells $(\mathrm{P}=0.2083)$, MMP-14 mRNA expression was significantly suppressed by epigenetic modifier treatment in RT-112 $(\mathrm{P}<0.0001)$, VMCUB-1 $(\mathrm{P}=0.0005)$ and $\mathrm{T}-24$ $(\mathrm{P}=0.0003)$ cell lines. The mRNA expression of all other MT-MMPs was increased in RT-4, RT-112, VMCUB-1 and $\mathrm{T}-24$ cell lines, the latter exhibited an alteration in MMP-16 and MMP-25 mRNA expression. However, MMP 25 mRNA 


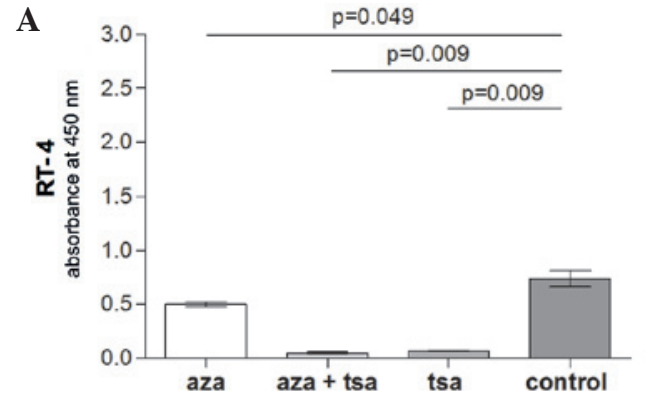

B

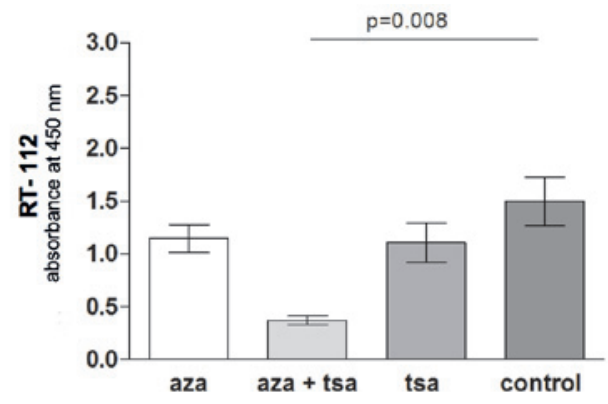

$\mathbf{C}$

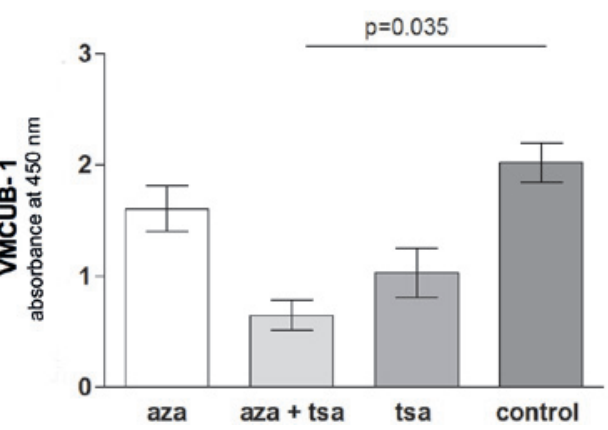

D

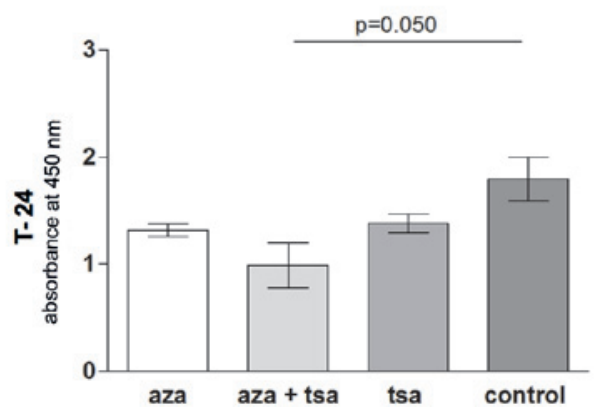

Figure 1. Proliferation of human urinary bladder cancer (A) RT-4, (B) RT-112, (C) VMCUB-1 and (D) T-24 cell lines following treatment with aza and TSA alone, and aza and TSA in combination. Untreated cells served as controls. aza, 5 aza 2' deoxycytidin; TSA, Trichostatin A.
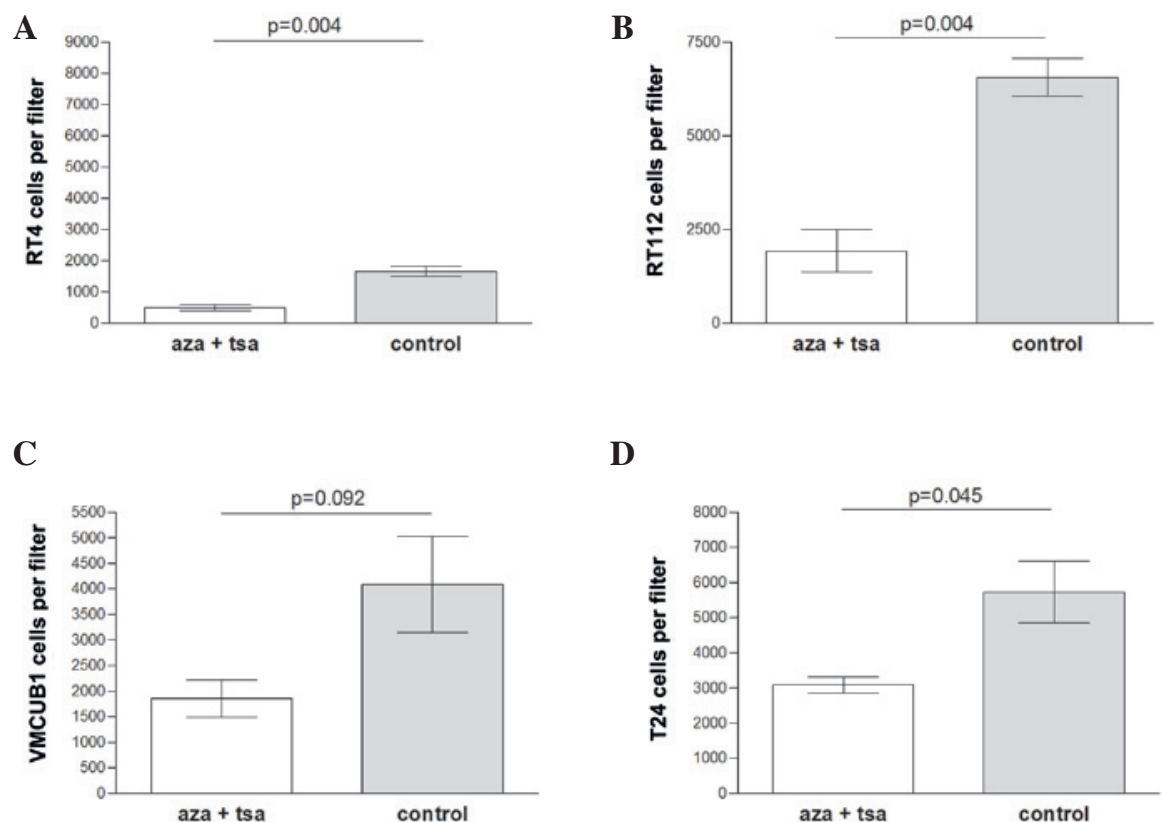

D

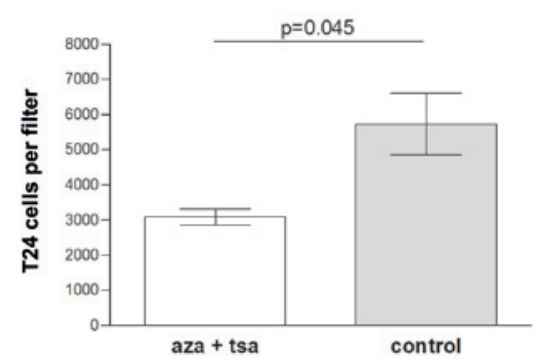

Figure 2. Migration of untreated and sequentially aza and TSA-treated human urinary bladder cancer (A) RT-4 (B) RT-112, (C) VMCUB-1 and (D) T-24 cells. Data are presented as the mean \pm standard deviation of three independent triple experiments. aza, 5-aza-2'-deoxycytidin; TSA, Trichostatin A.

was expressed only at a very low level. All P-values are provided in Table II.

Gelatinases. MMP-9 mRNA was not detected in the cell lines. By contrast to a significant mRNA suppression in RT-112 cells ( $\mathrm{P}=0.0206)$, MMP- 2 mRNA expression was not altered in RT-4 cells ( $\mathrm{P}=0.7801)$. MMP-2 mRNA expression was clearly induced in the high-grade cell lines at a low level (VMCUB-1, $\mathrm{P}=0.0002 ; \mathrm{T}-24, \mathrm{P}<0.0001$ ).

Collagenases. MMP-1 was induced significantly in all cell lines. MMP-8 mRNA increased from a low level. In all four cell lines, MMP-13 mRNA expression increased significantly from a high base level. All P-values are provided in Table II.

Stromelysins. MMP-3 mRNA was expressed in high-grade VMCUB-1 and T-24 cell lines at a high level, in contrast to RT-4 and RT-112 cell lines. However, only RT-4 and T-24 cells upregulated MMP-3 mRNA significantly $(\mathrm{P}=0.0001$ and $\mathrm{P}=0.0006$, respectively). The same result was observed for MMP-10 and MMP-11 mRNA, with the exception of MMP-11 in the T-24 cell line (Table II). 
A

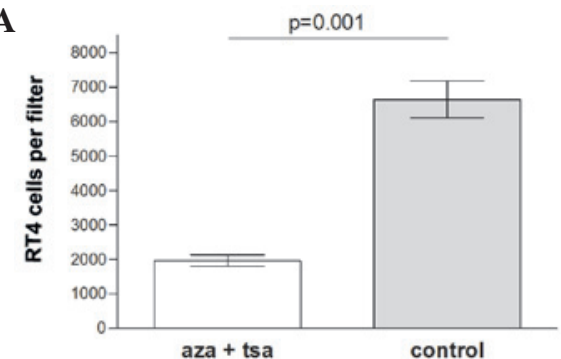

C

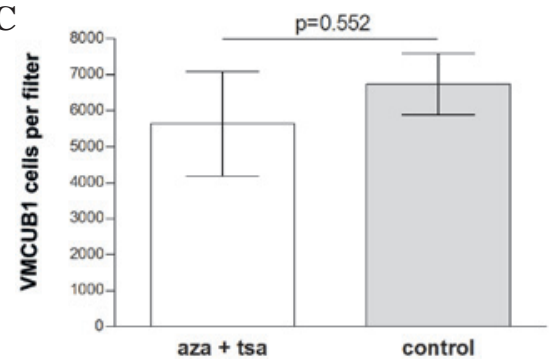

B

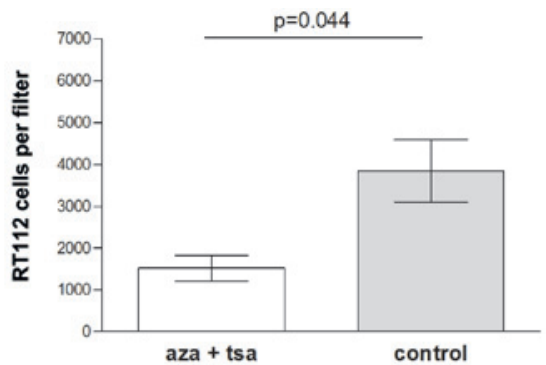

D

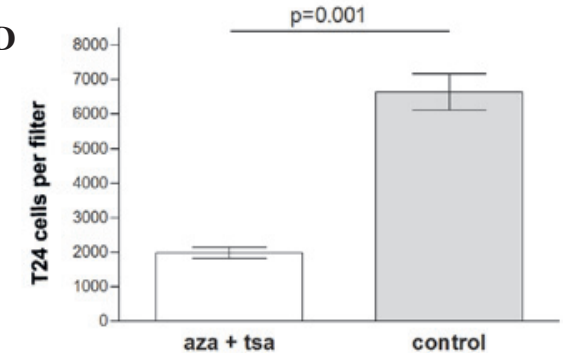

Figure 3. Invasion of untreated and sequentially aza and TSA-treated human urinary bladder cancer (A) RT-4 (B) RT-112, (C) VMCUB-1 and (D) T-24 cells Data are presented as the mean \pm standard deviation of three independent triple experiments. aza, 5-aza-2'-deoxycytidin; TSA, Trichostatin A.

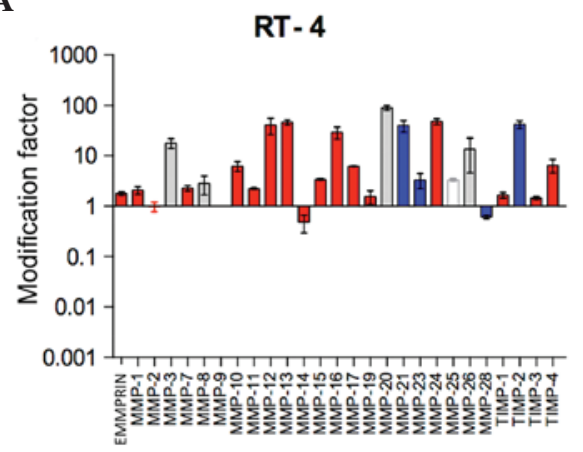

C

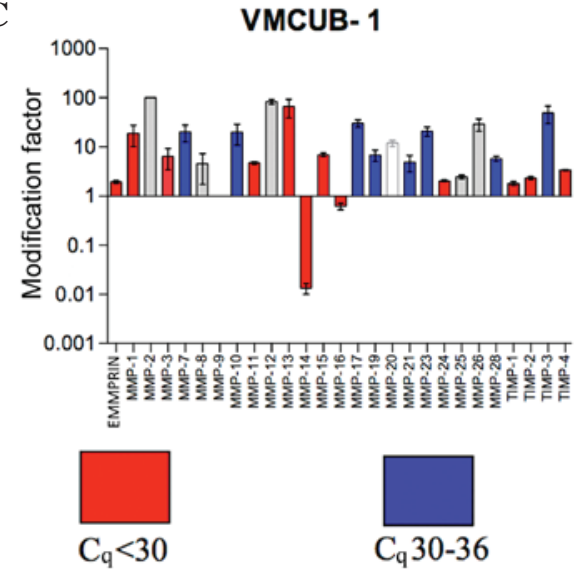

B

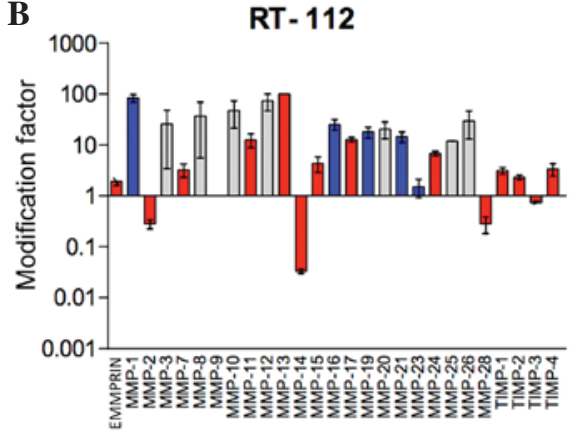

D

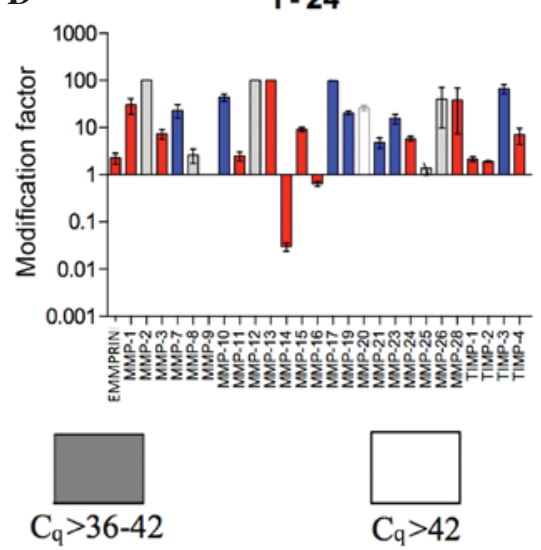

Figure 4. MMPs, TIMPs and mRNA expression in 5-aza-2'-deoxycytidin and Trichostatin A-treated human urinary bladder cancer (A) RT-4 (B) RT-112, (C) VMCUB-1 and (D) T-24 cells, using quantitative polymerase chain reaction. Values $>100$ have been equated with 100. The color of the column indicates the level of mRNA expression, according to the Cq. MMP-9 did not exhibit any expression and is not included. MMP, Matrix metalloproteinase; TIMP, tissue inhibitor matrix metalloproteinase; EMMPRIN, extracellular matrix metalloproteinase inducer.

Other MMPs. Notably, mRNA of MMP-12, which is typically expressed in macrophages, exhibited a high expression level in RT-4 cells and was significantly induced in other cell lines. MMP-28 mRNA was suppressed by epigenetic modifier treatment in RT-4 and RT-112 cells. The mRNA expression levels of MMP-19, -20, -21, -23 and -27 exhibited individual patterns, which were either stable or induced following treatment with epigenetic modifiers. P-values are provided in Table II. 
Table II. P-values for mRNA expression of MMPs, TIMs and EMMPRIN in human urinary bladder cancer cell lines agaisnt untreated cells.

\begin{tabular}{|c|c|c|c|c|}
\hline & \multicolumn{4}{|c|}{ Cell lines, P-value } \\
\hline & RT-4 & RT-112 & VMCUB-1 & $\mathrm{T}-24$ \\
\hline EMMPRIN & 0.0254 & 0.0193 & 0.0618 & 0.0518 \\
\hline MMP-1 & 0.0104 & 0.0010 & 0.0199 & 0.0015 \\
\hline MMP-2 & 0.7801 & 0.0206 & $0.0002^{\mathrm{a}}$ & $<0.0001^{\mathrm{a}}$ \\
\hline MMP-3 & 0.0001 & $0.1097^{\mathrm{a}}$ & 0.3396 & 0.0006 \\
\hline MMP-7 & 0.0009 & 0.0123 & 0.0027 & 0.0004 \\
\hline MMP-8 & 0.0611 & 0.0879 & 0.1041 & 0.0566 \\
\hline MMP-9 & $\mathrm{NE}$ & NE & $\mathrm{NE}$ & NE \\
\hline MMP-10 & 0.0108 & 0.0076 & 0.0068 & 0.0015 \\
\hline MMP-11 & 0.0099 & 0.0274 & 0.0048 & 0.0602 \\
\hline MMP-12 & 0.0003 & $0.0036^{\mathrm{a}}$ & $0.0023^{\mathrm{a}}$ & $<0.0001^{\mathrm{a}}$ \\
\hline MMP-13 & $<0.0001$ & 0.0002 & 0.0017 & $<0.0001$ \\
\hline MMP-14 (MT1-MMP) & 0.2083 & $<0.0001$ & 0.0005 & 0.0003 \\
\hline MMP-15 (MT2-MMP) & $<0.0001$ & 0.0036 & 0.0004 & 0.0002 \\
\hline MMP-16 (MT3-MMP) & 0.0011 & 0.0002 & 0.0201 & 0.0875 \\
\hline MMP-17 (MT4-MMP) & $<0.0001$ & $<0.0001$ & $<0.0001$ & 0.0130 \\
\hline MMP-19 & 0.8661 & 0.0002 & 0.0011 & $<0.0001$ \\
\hline MMP-20 & $<0.0001^{\mathrm{a}}$ & $0.0035^{\mathrm{a}}$ & $0.0008^{\mathrm{a}}$ & $0.0065^{\mathrm{a}}$ \\
\hline MMP-21 & $<0.0001$ & 0.0210 & 0.0127 & 0.0083 \\
\hline MMP-23 & 0.0534 & 0.6542 & 0.0009 & 0.0013 \\
\hline MMP-24 (MT5-MMP) & $<0.0001$ & 0.0054 & 0.0014 & $<0.0001$ \\
\hline MMP-25 (MT6-MMP) & $<0.0001^{\mathrm{a}}$ & $<0.0001$ & $0.0325^{\mathrm{a}}$ & $0.6737^{\mathrm{a}}$ \\
\hline MMP-26 & 0.1823 & 0.2333 & 0.1719 & 0.4009 \\
\hline MMP-28 & 0.0130 & 0.0307 & 0.0161 & 0.1305 \\
\hline TIMP-1 & 0.0506 & 0.0004 & 0.0026 & 0.1179 \\
\hline TIMP-2 & $<0.0001$ & 0.0051 & 0.0006 & 0.0025 \\
\hline TIMP-3 & 0.0106 & 0.1888 & 0.0002 & 0.0002 \\
\hline TIMP-4 & 0.0073 & 0.0797 & 0.0028 & 0.0094 \\
\hline
\end{tabular}

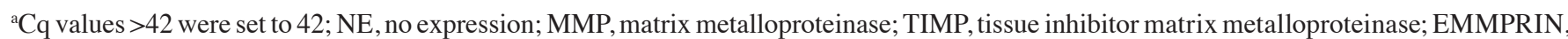
extracellular matrix metalloproteinase inducer; MT, membrane type.

TIMPs. TIMP-3 was upregulated following treatment with TSA and aza combination, which was at higher level in RT-4 and RT-112 cells compared to VMCUB-1 and T-24 cells. TIMP-1 and TIMP-2 mRNA was scantly expressed, but significantly upregulated in all four cell lines, with the exception of TIMP-2 mRNA in T-24 cells. Treatment with epigenetic modifiers significantly induced the expression of TIMP-4 mRNA in RT-4, VCUMB-1 and T-24 cell lines, whereas in RT-112 cells this appeared to be a statistical trend. All P-values are provided in Table II.

\section{Discussion}

Epigenetics may offer additional treatment options for solid malignancies. The present study analyzed the effects of the histone deacetylase inhibitor Trichostatin A (TSA) and the DNA methyltransferase inhibitor 5-aza-2'-deoxycytidine (aza) on proliferation, migration and invasion of four urothelial cancer cell lines with various proliferation characteristics. In addition, the present study analyzed the mRNA expression of a broad panel of MMPs, TIMPs and EMMPRIN following TSA and aza treatment.

For optimum treatment, the two inhibitors were combined and this treatment combination exhibited the strongest antiproliferative effects in all cell lines. This has already been reported by Karam et al (19) in urothelial carcinoma cell lines and Cecconi et al (20) in an endocrine pancreatic carcinoma cell line. The effect of the inhibitors may be associated with the re-expression of cell cycle regulatory proteins and the activation of key genes of the apoptotic cascade (21). In the present study, treatment with aza and TSA combination on the low-proliferating RT-4 cell line resulted in clear antiproliferative effects. This may be due to the switch-off of additional cell-cycle-promoting proteins or the switch-on of cell-cycle-controlling proteins. The requirement of a combined epigenetic modification, leading to a decreased proliferation in the other cell lines (RT-112, VMCUB-1 and T-24), suggests that there are pre-existing structural gene alterations of cell 
cycle promoting or controlling proteins, whose effects are affected by combined TSA and aza treatment.

Invasiveness is a complex function of migration and extracellular matrix remodelling. As summarized in Fig. 4 aza/TSA-treatment stimulated the expression of the majority of MMPs and TIMPs. Sato et al (22) observed increased invasiveness in pancreatic cancer cells and an induction of MMP-1, $-2,-3,-7,-9$ and -14 following aza treatment. In contrast to the other cell lines, in RT112 cells, aza/TSA-treatment suppressed MMP-2 and MMP-28 mRNA expression. Shukeir et al (23) identified a decreased MMP 2 expression triggered by gene methylation in highly invasive prostate cancer cell lines. Couillard et al (21) described an increased MMP-3 expression in colon cancer cell lines following demethylating treatment with aza. However, in that study MMP-10 expression was not affected by aza treatment. Furthermore, in B-cell lymphoma cells a MMP-10 induction, but not a MMP-3 induction, was observed (21). Chen et al (24) described a clear inhibitory effect on the invasiveness of bladder cancer cells treated with the histone deacetylase inhibitor valproic acid; however, inhibition of migration was not observed. Since, epigenetic modifiers induce antiproliferative effects, it is necessary to dissect antiproliferative from anti-migratory and anti-invasive effects. Therefore, the present study corrected migration and invasion assays against antiproliferative effects. With the exception of VMCUB-1 cells, a significant inhibition in migration and invasion was observed in all cell lines, and VMCUB-1 cells exhibited a trend towards reduced invasion. These various, somewhat contradictory, results suggest an epigenetic effect on the invasiveness and migratory behavior in a cell- or tissue-specific manner.

In the present study, MMP-14 suppression by aza/TSA treatment was a constant effect in all tested cell lines. MMP-14, also known as MT1-MMP, and TIMP-2 form an activating complex with proMMP-2 on the cell surface (25). As shown by qPCR in the present study, MMP-14 mRNA expression was suppressed, possibly resulting in a reduction of activating complexes. Selective inhibition of MMP-14 is capable of blocking invasion and tumour growth (26). Itoh and Seiki (27) underlined the essential role of MMP-14 in the regulation of invasion and migration in tumour cells via homodimerization on the cell surface for pericellular collagenolysis, a mechanism that has also been identified for the collagenase MMP-13 (28). Notably, MMP-13 was significantly induced in all cell lines in the present study following treatment with aza and TSA combination. Therefore, the reduction in invasion and migration in the present experiments may be explained by the inhibition of MMP-14 expression. Kitagawa et al (29) found that the mRNA of MMP-14 and MMP-15 was significantly overexpressed in urothelial carcinoma in comparison with normal mucosa. High mRNA expression of the two MMPs was associated with multilocular tumours (29). In contrast, mRNA expression of MMP-16, which is also a proMMP-2 activator, was detected at a much lower level without any particular association (29). In the present study, MMP-16 was significantly stimulated in the low grade cell lines RT-4 and RT-112. In contrast, this MMP-16 mRNA expression was suppressed in the high grade cell lines VMCUB-1 and T-24. In colorectal cancer and cancer cell lines, MMP-16 promoter hypermethylation was reported to be associated with a decreased mRNA expression (30). Treatment with 5-aza 2'-deoxycytidine restored this mRNA expression in colorectal cancer cell lines (30). Knockdown of mRNA expression was associated with cell migration, re-expression and overexpression of genes and proteins, with reduced migration (30). These observations confirm the findings from the present study regarding mRNA expression of MMP-16 in the low grade urothelial cancer cell lines, RT-4 and RT-112, but are in contrast to the findings of the present study that regard migration and the effects in the high grade cell lines, VMCUB-1 and T-24. Therefore, it is likely that regulatory pathways are more complex. Furthermore, Moon et al (30) did not consider the potential anti-proliferative effects of aza treatment. TIMP proteins are genuine inhibitors of MMPs, but they also perform additional functions. TIMP-3 overexpression is associated with the induction of apoptosis $(31,32)$, while TIMP-1 and TIMP-2 protect B cells and melanoma cells, respectively, from apoptosis (33). In the present study, TIMP mRNA expression was increased in all cell lines. An alteration in the MMP/TIMP ratio towards TIMPs and suppression of MMP-14, coupled with inhibited migratory properties, may be essential for the observed reduced invasiveness of RT-4, RT-112 and T-24 cell lines. In VMCUB-1 cells, no effects on migration and invasion were observed; therefore, other extracellular matrix remodelling proteinases, including urokinase and plasminogen activator-1, may be of importance in this cell line.

In conclusion, the present study revealed that the epigenetic modifications of aza and TSA suppressed the motility and invasiveness of three out of four urothelial cancer cell lines. The inhibitory effect on cell motility appears to be crucial for reduced invasive properties. However, even a broad spectrum mRNA analysis of the MMP/TIMP axis does not sufficiently explain the loss of invasiveness, since it leaves no scope for functional conclusions, such as the homodimerization of MMP-14 or MMP-13. Further complex urothelial tumour models should be applied to investigate whether epigenetic therapeutic approaches may be used in urothelial cancer.

\section{References}

1. Kanwal R and Gupta S: Epigenetic modifications in cancer. Clin Genet 81: 303-311, 2012.

2. Ades L and Santini V: Hypomethylating agents and chemotherapy in MDS. Best Pract Res Clin Haematol 26: 411-419, 2013.

3. Kim TK, Gore SD and Zeidan AM: Epigenetic therapy in acute myeloid leukemia: Current and future directions. Semin Hematol 52: 172-183, 2015.

4. Boumber Y and Issa JP: Epigenetics in cancer: What's the future? Oncology (Williston Park) 25: 220-226, 228, 2011.

5. Montero AJ, Diaz-Montero CM, Mao L, Youssef EM, Estecio M, Shen L and Issa JP: Epigenetic inactivation of EGFR by $\mathrm{CpG}$ island hypermethylation in cancer. Cancer Biol Ther 5: 1494-1501, 2006.

6. Bauman J, Verschraegen C, Belinsky S, Muller C, Rutledge T, Fekrazad M, Ravindranathan M, Lee SJ and Jones D: A phase I study of 5-azacytidine and erlotinib in advanced solid tumor malignancies. Cancer Chemother Pharmacol 69: 547-554, 2012.

7. Vigushin DM, Ali S, Pace PE, Mirsaidi N, Ito K, Adcock I and Coombes RC: Trichostatin A is a histone deacetylase inhibitor with potent antitumor activity against breast cancer in vivo. Clin Cancer Res 7: 971-976, 2001.

8. Ailenberg $\mathbf{M}$ and Silverman $\mathbf{M}$ : Trichostatin A-histone deacetylase inhibitor with clinical therapeutic potential-is also a selective and potent inhibitor of gelatinase A expression. Biochem Biophys Res Commun 298: 110-115, 2002. 
9. Christman JK: 5-Azacytidine and 5-aza-2'-deoxycytidine as inhibitors of DNA methylation: mechanistic studies and their implications for cancer therapy. Oncogene 21: 5483-5495, 2002.

10. Ferguson AT, Lapidus RG, Baylin SB and Davidson NE: Demethylation of the estrogen receptor gene in estrogen receptor-negative breast cancer cells can reactivate estrogen receptor gene expression. Cancer Res 55: 2279-2283, 1995.

11. Yuecheng Y, Hongmei L and Xiaoyan X: Clinical evaluation of E-cadherin expression and its regulation mechanism in epithelial ovarian cancer. Clin Exp Metastasis 23: 65-74, 2006.

12. Kang SH, Choi HH, Kim SG, Jong HS, Kim NK, Kim SJ and Bang YJ: Transcriptional inactivation of the tissue inhibitor of metalloproteinase-3 gene by dna hypermethylation of the 5 '-CpG island in human gastric cancer cell lines. Int J Cancer 86 : 632-635, 2000.

13. Izawa JI, Slaton JW, Kedar D, Karashima T, Perrotte P, Czerniak B, Grossman HB and Dinney CP: Differential expression of progression-related genes in the evolution of superficial to invasive transitional cell carcinoma of the bladder. Oncol Rep 8: 9-15, 2001

14. Hara I, Miyake H, Hara S, Arakawa S and Kamidono S: Significance of matrix metalloproteinases and tissue inhibitors of metalloproteinase expression in the recurrence of superficial transitional cell carcinoma of the bladder. J Urol 165: 1769-1772, 2001.

15. National Institute for Health and Care Excellence: Bladder cancer: Diagnosis and management. NICE Guideline 2. National Collaborating Centre for Cancer, Cardiff, 2015. https://www. nice.org.uk/guidance/ng2/resources/bladder-cancer-diagnosis -and-management-of-bladder-cancer-51036766405. Accessed: June 10, 2016.

16. Elmamoun MH, Christmas TJ and Woodhouse CR: Destruction of the bladder by single dose Mitomycin C for low-stage transitional cell carcinoma (TCC) - avoidance, recognition, management and consent. BJU Int 113:E34-E38, 2014

17. Pommier JD, Ben Lasfar N, Van Grunderbeeck N, Burdet C, Laouénan C, Rioux C, Pierre-Audigier C, Meybeck A, Choudat L, Benchikh A, et al: Complications following intravesical bacillus Calmette-Guerin treatment for bladder cancer: A case series of 22 patients. Infect Dis (Lond) 47: 725-731, 2015.

18. Livak KJ and Schmittgen TD: Analysis of relative gene expression data using real-time quantitative PCR and the 2(-Delta Delta C(T)) Method. Methods 25: 402-408, 2001.

19. Karam JA, Fan J, Stanfield J, Richer E, Benaim EA, Frenkel E, Antich P, Sagalowsky AI, Mason RP and Hsieh JT: The use of histone deacetylase inhibitor FK228 and DNA hypomethylation agent 5 -azacytidine in human bladder cancer therapy. Int J Cancer 120: 1795-1802, 2007.

20. Cecconi D, Donadelli M, Dalla Pozza E, Rinalducci S, Zolla L, Scupoli MT, Righetti PG, Scarpa A and Palmieri M: Synergistic effect of trichostatin A and 5-aza-2'-deoxycytidine on growth inhibition of pancreatic endocrine tumour cell lines: A proteomic study. Proteomics 9: 1952-1966, 2009.
21. Couillard J, Demers M, Lavoie G and St-Pierre Y: The role of DNA hypomethylation in the control of stromelysin gene expression. Biochem Biophys Res Commun 342: 1233-1239, 2006.

22. Sato N, Maehara N, Su GH and Goggins M: Effects of 5-aza-2'-deoxycytidine on matrix metalloproteinase expression and pancreatic cancer cell invasiveness. J Natl Cancer Inst 95: 327-330, 2003

23. Shukeir N, Pakneshan P, Chen G, Szyf M and Rabbani SA: Alteration of the methylation status of tumor-promoting genes decreases prostate cancer cell invasiveness and tumorigenesis in vitro and in vivo. Cancer Res 66: 9202-9210, 2006.

24. Chen CL, Sung J, Cohen M, Chowdhury WH, Sachs MD, Li Y, Lakshmanan Y, Yung BY, Lupold SE and Rodriguez R: Valproic acid inhibits invasiveness in bladder cancer but not in prostate cancer cells. J Pharmacol Exp Ther 319: 533-542, 2006.

25. Kinoshita T, Sato H, Okada A, Ohuchi E, Imai K, Okada Y and Seiki M: TIMP-2 promotes activation of progelatinase A by membrane-type 1 matrix metalloproteinase immobilized on agarose beads. J Biol Chem 273: 16098-16103, 1998

26. Devy L, Huang L, Naa L, Yanamandra N, Pieters H, Frans N, Chang E, Tao Q, Vanhove M, Lejeune A, et al: Selective inhibition of matrix metalloproteinase-14 blocks tumor growth, invasion, and angiogenesis. Cancer Res 69: 1517-1526, 2009.

27. Itoh Y and Seiki M: MT1-MMP: A potent modifier of pericellular microenvironment. J Cell Physiol 206: 1-8, 2006.

28. Leeman MF, Curran S, Murray GI: The structure, regulation, and function of human matrix metalloproteinase-13. Crit Rev Biochem Mol Biol 37: 149-66, 2002.

29. Kitagawa Y, Kunimi K, Ito H, Sato H, Uchibayashi T, Okada Y, Seiki $\mathrm{M}$ and Namiki M: Expression and tissue localization of membrane-types 1,2, and 3 matrix metalloproteinases in human urothelial carcinomas. J Urol 160: 1540-1545, 1998.

30. Moon JW, Choi JH, Lee SK, Lee YW, Lee JO, Kim N, Lee HJ, Seo JS, Kim J, Kim HS, et al: Promoter hypermethylation of membrane type 3 matrix metalloproteinase is associated with cell migration in colorectal adenocarcinoma. Cancer Genet 208: 261-270, 2015.

31. Baker AH, George SJ, Zaltsman AB, Murphy G and Newby AC: Inhibition of invasion and induction of apoptotic cell death of cancer cell lines by overexpression of TIMP-3. Br J Cancer 79: 1347-1355, 1999.

32. Fata JE, Leco KJ, Voura EB, Yu HY, Waterhouse P, Murphy G, Moorehead RA and Khokha R: Accelerated apoptosis in the Timp-3-deficient mammary gland. J Clin Invest 108: 831-841, 2001.

33. Valente P, Fassina G, Melchiori A, Masiello L, Cilli M, Vacca A, Onisto M, Santi L, Stetler-Stevenson WG and Albini A: TIMP-2 over-expression reduces invasion and angiogenesis and protects B16F10 melanoma cells from apoptosis. Int J Cancer 75: 246-253, 1998. 